\title{
Characteristics of basal ice at Engabreen, northern Norway
}

\author{
Peter Jansson, \\ Department of Physical Geography, Stockholm University, S-106 91 Stockholm, Sweden \\ JACK KOHLER, \\ Glacier and Snow Section, Norwegian Water Resources and Energy Administration, P.O. Box 5091, N-0301 Oslo, Norway \\ Veijo A. Pohjola \\ Byrd Polar Research Center, 108 Scoll Hall, 1090 Carmack Road, Columbus, OH 43210-1002, U.S.A.
}

\begin{abstract}
Subglacial intakes in a tunnel system underneath Engabreen, northern Norway, provide access to the underside of a $200 \mathrm{~m}$ thick glacier. Detailed observations and measurements were made in several ice tunnels melted out along the glacier bed. A 20-200 cm thick basal sediment layer is overlain by clean glacier ice. Stratigraphy is complex, with alternating sediment-rich and sediment-free layers, and pervasive shearing. Throughout the basal ice are numerous spheroidal water pockets, which increase in both size and degree of elongation with distance from the bed. Ice cores were retrieved from ice-tunnel walls for sediment, cation and isotope analysis. Our observations and measurements provide evidence for both accretion in and water movement through the basal ice. This supports the modification to classical regelation theory proposed recently by Lliboutry in which water flow in the vein network is required to achieve net accretion of regelation layers.
\end{abstract}

\section{INTRODUGTION}

Studies of frontal ice and ice cores have shown that polar ice masses typically have a layer of basal sediment-rich ice measuring tens of meters. Debris-rich basal ice is also found in temperate ice (Souchez and Lorrain, 1978; Lawson, 1979; Souchez and de Groote, 1985; Sharp and others, 1994), but the debris-rich layers are generally thinner (decimeter- to meter-scale) than in polar ice masses.

Incorporation of sediment in temperate ice is thought to be predominantly through regelation, a process originally proposed in connection with basal sliding (Weertman, 1957). Pressure-induced melting of basal ice on the stoss sides of bumps produces water which flows along the ice/bed interface to the lee side. There it freezes again, incorporating any sediment present on the bed. Sediment accretion is limited, however, by the size of the largest bump around which the basal ice is regelating; sediment-rich ice layers formed in the lee of one bump are presumably melted away at the next bump of similar size.

Robin (1976) pointed out that pressure-melting should occur throughout a certain thickness in temperate basal ice, not just at the ice/bed interface. Furthermore, this water should be free to move through the vein network between ice crystals. Lliboutry (1993) quantitatively demonstrated the effect of water permeating through basal ice; instead of melting the regelation layer created by the previous bump, water is squeezed out of the ice in front of the bump and forced to the low-pressure zone on the lee side of the bump, where it freezes again. The important difference between Weertman and RobinLliboutry regelation theory is that the latter allows net accretion of basal regelation ice and sedimentary layers as the ice flows down-glacier.

To differentiate between regelation and unrefrozen ice, previous studies (summarized in Souchez and Lorrain (1991)) have analyzed basal ice samples for sediment concentrations and size characteristics, oxygen- and hydrogen-isotopic content, and ionic content. Many of these studies, however, use ice retrieved from locations near the margin, and atmospheric conditions may affect regelation processes.

In this study, we use basal ice samples collected from beneath the center of a $200 \mathrm{~m}$ thick temperate glacier, Engabreen, in northern Norway. Engabreen is one of the outlet glaciers draining the Svartisen ice cap. It lies in a narrow valley that channels ice from the plateau above (maximum altitude $\sim 1575 \mathrm{~m}$ a.s.l.) down to the terminus at $\sim 90$ ma.s.l (Ostrem and others, 1973; Fig. 1). The Norwegian Water Resources and Energy Administration (NVE) has established a research facility, the Svartisen Glaciological Observatory, in a bedrock tunnel system used to tap subglacial water for energy production. A side-tunnel off the main tunnel system is reserved for glaciological research, emerging at the glacier bed at 
a)

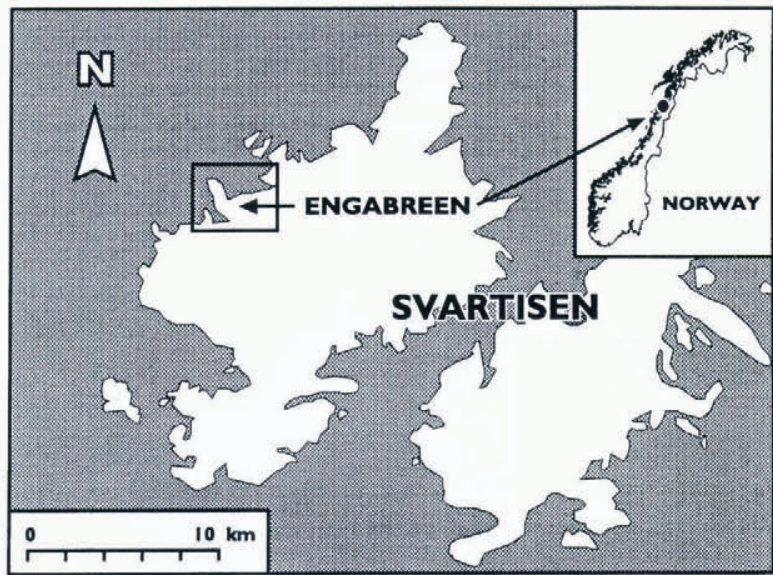

b)

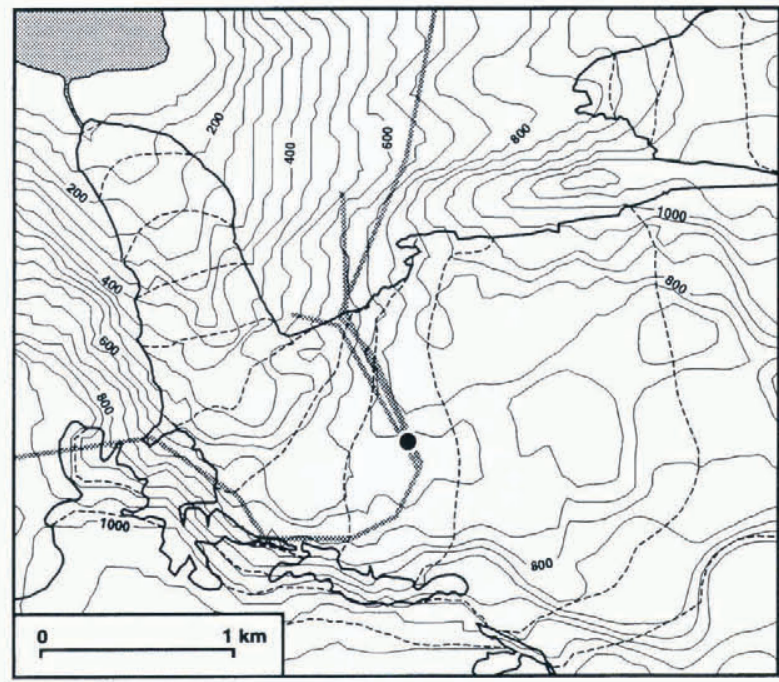

Fig. 1. (a) Location map. (b) Topographic map of Engabreen, with subglacial surface determined from radar measurements, ice-surface contours (dashed lines), tunnel system (grey lines) and location of the research tunnel (black circle).

$630 \mathrm{~m}$ a.s.l., in an area where the glacier is approximately $200 \mathrm{~m}$ thick. From this vantage point, ice tunnels can be melted out along the glacier bed using hot water. Figure 2 shows the basal topography around the research tunnel (W1) surveyed in the floor of ice tunnels melted in earlier, unpublished investigations. Ice flow at the surface and at the bed is roughly parallel. Surface velocity is about $1.0 \mathrm{~m} \mathrm{~d}^{-1}$, and basal sliding is about $10-20 \mathrm{~cm} \mathrm{~d}^{-1}$.

The bedrock in this area consists mainly of schist and gneiss, with calcite-filled cracks and veins throughout. While the bed does have patches of thin till, it consists predominantly of bare rock. Topography is steep and undulatory. Bumps, as such, have wavelengths of roughly $1-10 \mathrm{~m}$ and heights of $0.1-1.0 \mathrm{~m}$. A steep wall to the northwest of the $\mathrm{Wl}$ opening rises straight up at least $5 \mathrm{~m}$, and is undercut near the base to form an overhang.

In February 1994, several ice tunnels were melted out under Engabreen over a 1 week period (Fig. 2). We mapped rough stratigraphic profiles of the basal debris layer by measuring, photographing and sketching the tunnel walls. We retrieved ice "cores", wedges of ice cut from the ice-tunnel walls with a chain-saw, for isotopic and chemical analysis. Additional ice samples were taken from the glacier margin, and water samples were taken

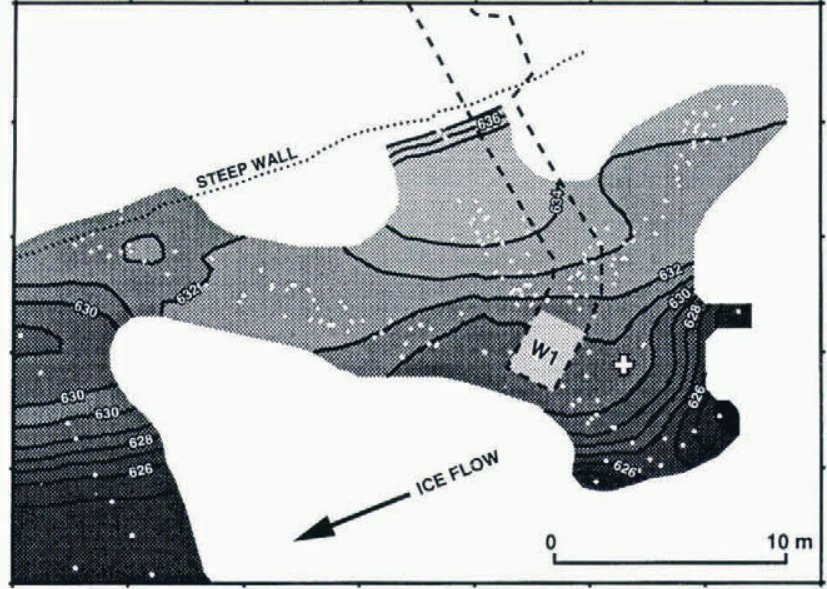

Fig. 2. Bed lopography in the vicinity of the research tunnel (heavy dashed line), opening where the tunnel emerges at the bed (W1) and survey points used to construct the subglacial topography contours (white dots). North is up.

from the proglacial stream and from water pouring out of cracks and boreholes in the rock tunnels.

\section{BASAL STRATIGRAPHY}

Upon melting a tunnel, we encounter a complex suite of sediment-rich ice layers overlain by clear sediment-free and bubble-free ice. Total thickness of the sediment-rich ice typically varies from about 0.2 to $2 \mathrm{~m}$, when measured perpendicularly to the bed. Near the steep wall, to the west of $\mathrm{Wl}$, the sediment layers drape over the wall in such a way that all the ice in the overhang is filled with sediment-rich ice.

Identifying distinct stratigraphic units in the basal ice is problematic, not only because of the often smooth gradation between layers which are difficult to characterize from their appearance, but also because of confusion in the terminology used in the literature.

In places the finer-grained fraction of the sediments is gathered in small clusters or "clots", as described earlier (e.g. Knight and others, 1994). Elsewhere we identify a "dispersed" layer, consisting of single-sediment particles in a matrix of clean ice (note that our dispersed layer is different from Lawson's (1979)). There are also extensive banded layers, consisting of alternating layers of clotted and relatively sediment-free ice. In some places the bands are sub-parallel to the bedrock floor, in other places they are heavily contorted and folded. Clots are generally elongate in the flow direction, and at higher sediment concentrations form roughly continuous sub-parallel bands of sediments.

Sediment content ranges from cloudy ice, which is almost completely sediment-free, to debris-rich layers with very large sediment clasts up to roughly $10-100 \mathrm{~cm}$ in diameter. There is an especially high concentration of larger clasts in the basal layers close to the steep wall and in the overhang.

A feature not noted before in the literature is a pervasive convoluted layer found about $5-25 \mathrm{~cm}$ below the transition between sediment-rich and clear ice. The layer is characterized by (1) convoluted banding, (2) a 
marked increase in sediment content and size, (3) a large number of water-filled voids irregularly distributed along the layer, all of which have a more deformed and irregular shape than the spheroidal water pockets found elsewhere in the basal ice, and (4) clear-ice "augen" features around some of the larger sediment particles, typically small gravel to gravel in size. The latter features appear similar to those found around phenocrysts in sheared rocks. The orientation of the pressure shadow is consistent with the flow direction and the sense of basal shear.

\section{WATER POCKETS}

A remarkable feature of the basal ice is the presence of numerous water-filled voids, or water pockets. These are found throughout the vertical sequence, from the bed to as far up as we melted, $4-5 \mathrm{~m}$ above the bed. They are much more common in the clean-ice layers, although limited numbers are found in the sediment layers as well. They are small (about $1 \mathrm{~cm}$ ) and generally spheroidal near the bed, but increase in size and become progressively more elongate with distance away from the bed. They are elongated in the ice-flow direction and seem to be grouped in swarms. The largest water pockets we observed are $2 \mathrm{~m}$ long or more at a height of about $4 \mathrm{~m}$ from the bed, and contain about 201 of water. Most are free of sediment, although some have a layer of fine particles settled out on the bottom.

\section{ICE CORES}

\section{Analysis}

Three ice cores were extracted from the tunnels. None of the cores reached exactly to the bed, for during meltingout of the ice-tunnels a certain thickness of the lowermost layer was unavoidably lost. The thickness of the core we describe here, core $\mathrm{B}$, is about $2 \mathrm{~cm}$. The location of core $\mathrm{B}$ is shown in Figure 2.

Core B was divided into 86 samples, each approximately $15 \mathrm{~mm}$ thick, to be analyzed for sediment, isotopic and cation content. Vertical thin sections were also taken from the core for crystallographic analysis (not reported here), photographic documentation and detailed stratigraphy (Fig. 3).

The 86 ice samples were weighed, and then melted and filtered through Munktell paper filters to retrieve the sediments. The water was refiltered through $45 \mu \mathrm{m}$ filters before isotope and cation analysis. Isotope analysis was performed at the Institute of Earth Sciences, Uppsala University, with errors of $0.1 \%$ and $0.03 \%$ for $\delta^{18} \mathrm{O}$ and $\delta \mathrm{D}$, respectively. Cation analysis was performed at the Department of Meteorology, Stockholm. Figure 4 shows the results of the sediment, cation and isotope analyses.

\section{Results}

\section{Sediments}

As discussed in the basal stratigraphy section, we identify

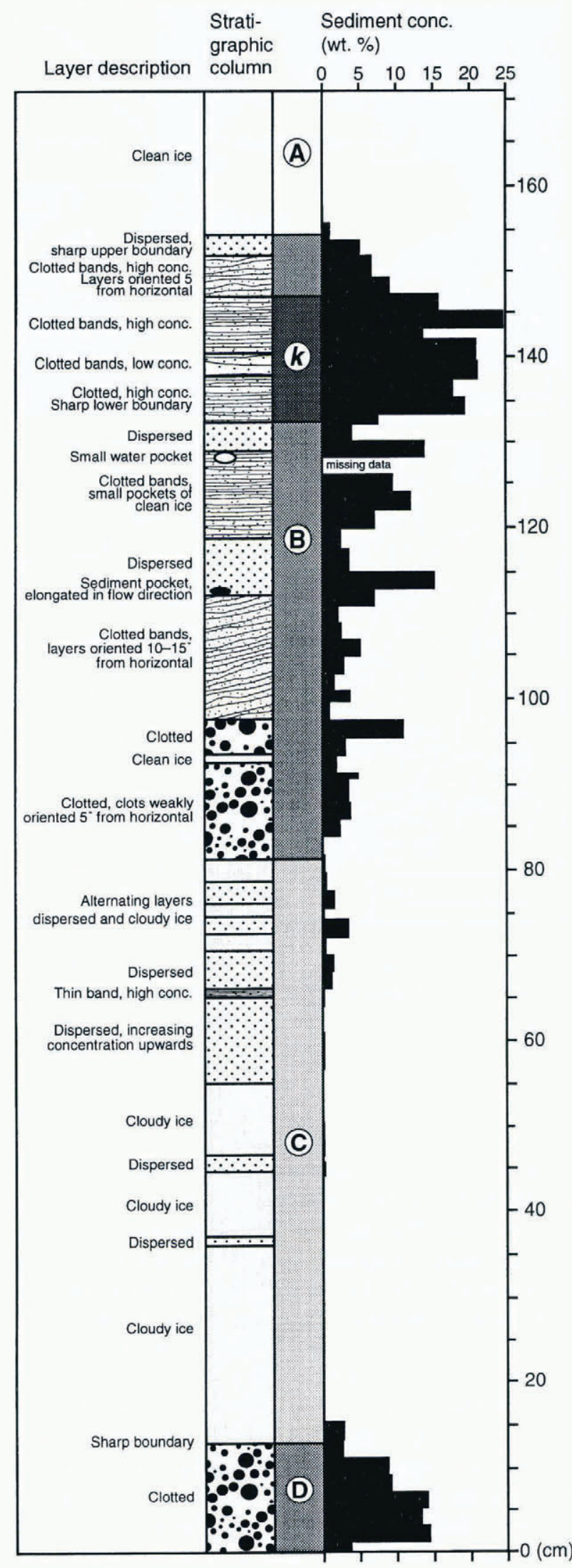

Fig. 3. Description of the sediment layers in core $B$, with stratigraphic column, location of units $A-D$ and the convoluted laver $(k)$, and sediment concentration, all as a function of core length. Glacier bed is at about $-2 \mathrm{~cm}$.

five characteristic ice types: clean ice, cloudy ice, dispersed sediments, clotted sediment, and banded layers. Figure 3 is a plot of the sediment concentration 

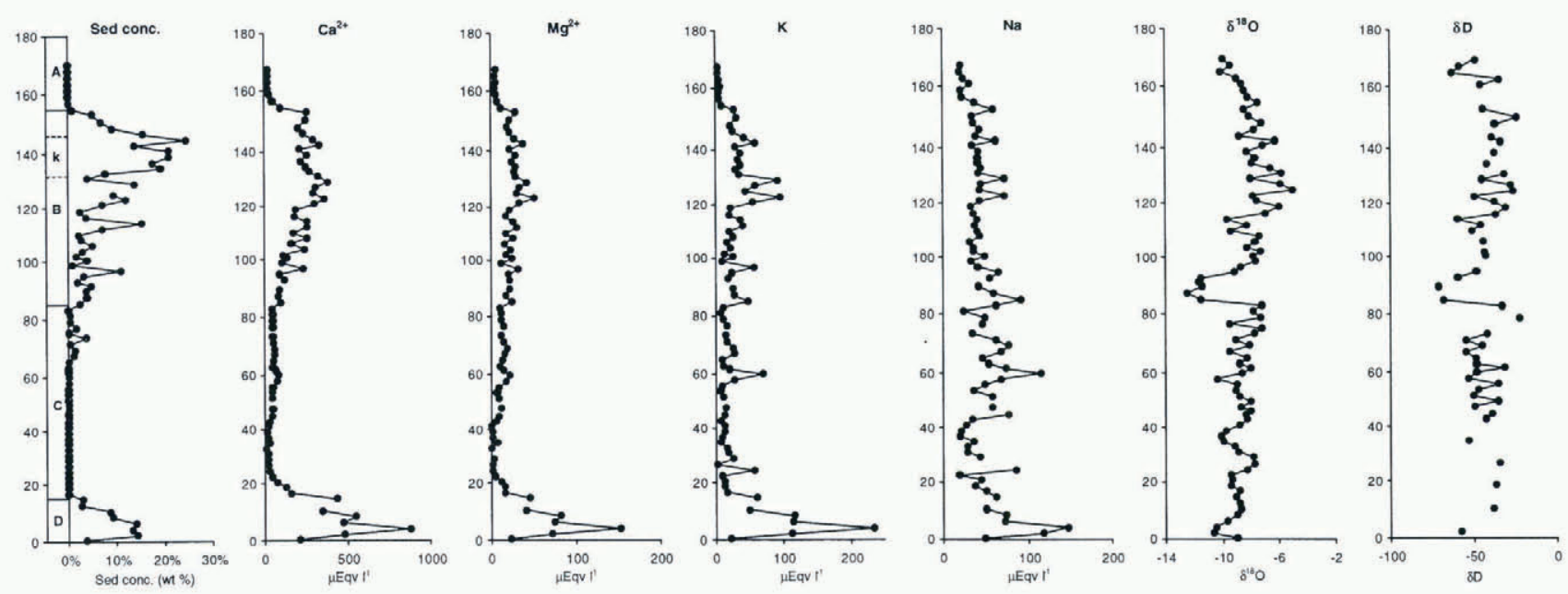

Fig. 4. Sediment content, cation concentration and isotope content plotted against core length. Glacier bed is at about $-2 \mathrm{~cm}$.

and a summary of the detailed stratigraphy. We identify four major units (starting from the top):

(A) Sediment-free glacier ice, down to $158 \mathrm{~cm}$. Unit A has no significant sediment content, and is in sharp contact with unit $B$.

(B) A sediment-rich layer, from 55 to $158 \mathrm{~cm}$, containing a complex assemblage of sediment structures, including the convoluted layer at $140-145 \mathrm{~cm}$. Unit $\mathrm{B}$ shows great diversity in sediment concentration and in the appearance of the sediment. It consists of: (a) clotted layers; (b) banded layers, at various angles to the bed ranging from sub-parallel to about 20-50 ; (c) dispersed layers; (d) a water-filled void; (e) a sediment pocket, elongated in the direction of flow; and ( $\mathrm{f}$ ) the convoluted layer ( $\mathrm{k}$ in Fig. 3 ).

(C) A layer of cloudy ice, from 13 to $55 \mathrm{~cm}$. Unit C is characterized by generally low sediment concentration, increasing somewhat up-core. Sediment is predominantly the finest fraction, which gives the ice its milky appearance. Sediment occurs as dispersed grains except at $58 \mathrm{~cm}$, where there is a distinct sheet of clotted sediment $1-2 \mathrm{~mm}$ thick.

(D) A lower sediment-rich layer, from 0 to $13 \mathrm{~cm}$. Unit D is characterized by clotted sediment (clot diameter about $5 \mathrm{~mm}$ ) with some interspersed single grains in the ice matrix. Clots seem to lie in "bands" $45^{\circ}$ from the horizontal plane, but individual clots are only weakly elongated in the direction of flow. The upper boundary of this unit is distinct, and there are no apparent gradients in sediment content.

\section{Cations}

Concentrations of the major cations $\mathrm{Na}^{+}, \mathrm{K}^{+}, \mathrm{Mg}^{2+}$ and $\mathrm{Ca}^{2+}$ ) have been used to distinguish unaltered basal ice from ice that has been refrozen at the glacier sole (Souchez and Lorrain, 1991). The main source of $\mathrm{Na}^{+}$ and $\mathrm{K}^{+}$is thought to be from sea salt via atmospheric precipitation, while $\mathrm{Mg}^{2+}$ and $\mathrm{Ca}^{2+}$ are alkaline-earth metals, derived predominantly from weathered rock. Therefore, $\mathrm{Na}^{+}$and $\mathrm{K}^{+}$should have higher concentrations in unaltered glacier ice, and $\mathrm{Mg}^{2+}$ and $\mathrm{Ca}^{2+}$ in regelated ice.
In core $\mathrm{B}$, the distribution of $\mathrm{Ca}^{2+}$ and $\mathrm{Mg}^{2+}$ follows the sediment concentration, while $\mathrm{Na}^{+}$concentration decreases away from the bed and is not correlated with sediment concentration at all (Fig. 4). $\mathrm{K}^{+}$is intermediate; where there are high concentration spikes in $\mathrm{Na}^{+}$, there are likewise spikes in $\mathrm{K}^{+}$, but otherwise $\mathrm{K}^{+}$ generally follows the sediment concentration. Concentrations of $\mathrm{Ca}^{2+}, \mathrm{Mg}^{2+}$ and $\mathrm{K}^{+}$fall off rapidly at the transition between sediment-rich and clean ice, that is, between units $\mathrm{B}$ and $\mathrm{A}$ and between units $\mathrm{D}$ and $\mathrm{C}$.

It is not unlikely that at least part of the $\mathrm{Ca}^{2+}$ and $\mathrm{Mg}^{2+}$ signal is due to secondary leaching of ions from sediment during melting and filtering of the ice samples, a procedure which takes 5-10 min. Laboratory experiments have demonstrated significant and rapid dissolution in comparably short times, using mixtures of pure water and silt- and clay-sized proglacial sediments Brown and others, 1994). If the ice surrounding the sediment particles was extremely poor in ions to begin with, then leaching would present a significant problem. One solution would be to apply a correction factor for secondary leaching. This is beyond the scope of this paper, however, and instead we restrict our discussion to the relative values of ion concentrations in the core.

All cations in core B have significantly higher concentrations in basal unit D than in unit B, despite similar sediment concentrations in the two units. Peak and average concentrations of $\mathrm{Ca}^{2+}, \mathrm{Mg}^{2+}$ and $\mathrm{K}^{+}$are roughly two times higher in unit $\mathrm{D}$ than in unit $\mathrm{B}$ (Fig. 4; Table 1). Furthermore, it is significant that the clean-ice samples just above the transition between units $\mathrm{A}$ and $\mathrm{B}$, and between units $\mathrm{C}$ and $\mathrm{D}$, contain relatively high concentrations of $\mathrm{Ca}^{2+}$ and $\mathrm{Mg}^{2+}$. Concentrations gradually diminish away from the contact, and reach "normal" clean-ice levels at 3 and $10 \mathrm{~cm}$ away from the contact for units $\mathrm{A}$ and $\mathrm{C}$, respectively.

Finally, water from water pockets in the clear ice (equivalent to unit $\mathrm{A}$, but from a different area) has ionic values that are low compared with the average for core B but significantly higher than the average values for unit $\mathrm{A}$ (Table 1).

\section{Isotopes}

All core $\mathrm{B}$ samples were analyzed for $\delta^{18} \mathrm{O}$. For various 
Table 1. Characteristics of the ice and water in and around Engabreen, northern Norway

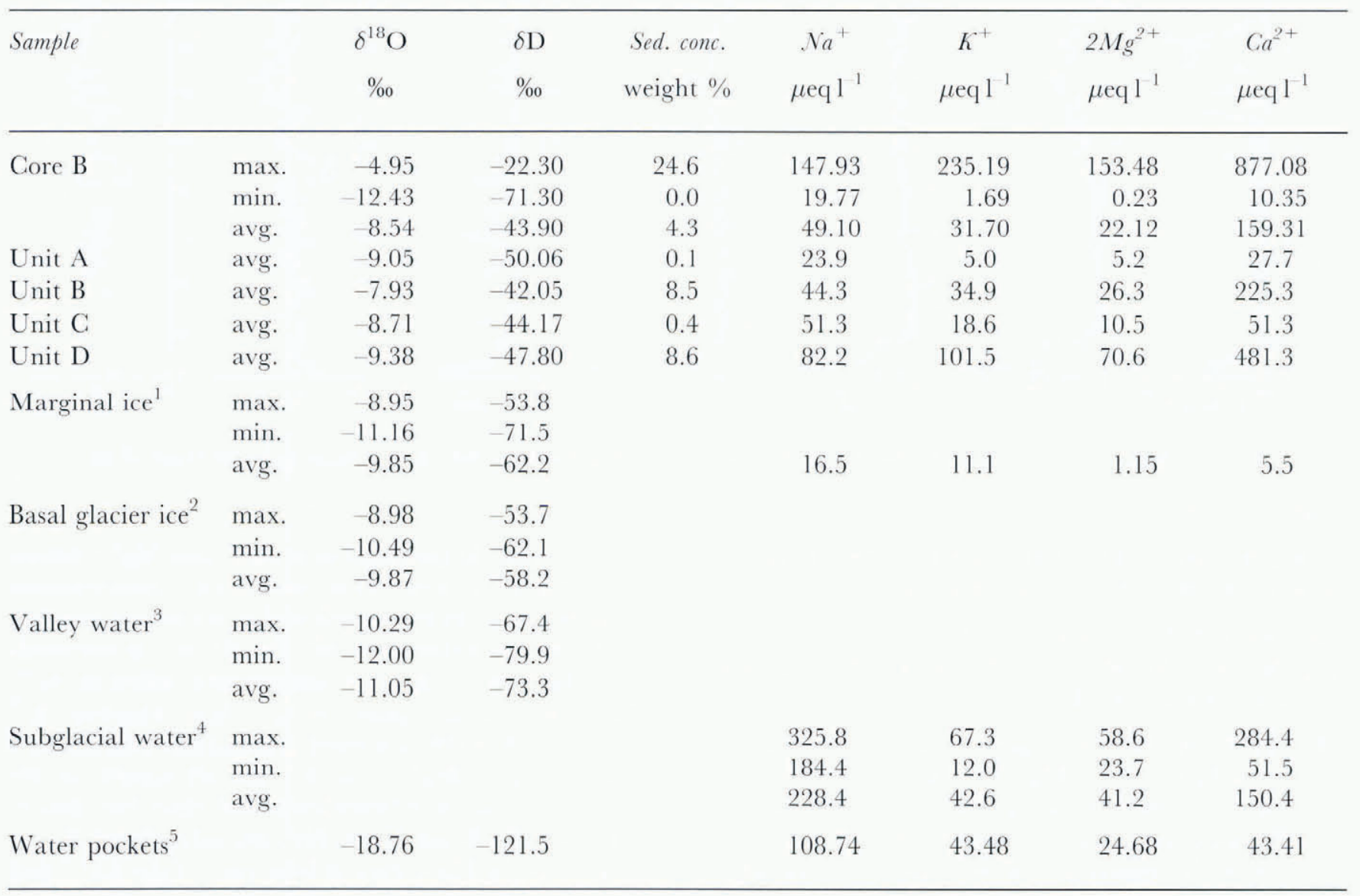

1 Isotopes measured on six samples, ions on two samples.

2 Isotopes measured on four samples from tunnel roof and walls of water pockets.

${ }^{3}$ Isotopes measured on one sample from the proglacial stream, two samples from two non-glaciated valley side-streams and one sample from the lake in front of Engabreen.

4 Ions measured on one sample of water flowing from cracks in the rock tunnel, two samples of water from subglacial intakes and one sample from the proglacial stream.

${ }^{5}$ Isotope and ion analysis performed on different water pockets.

reasons, the $\delta \mathrm{D}$ analysis is incomplete. Both isotopic signals are quite variable, and show similar trends (Fig. 4). The co-isotopic diagram (Fig. 5), however, shows more scatter than expected in the relation between the two isotopes. We have reason to suspect that some of the $\delta \mathrm{D}$ samples may have been altered by evaporation. We present the $\delta \mathrm{D}$ data for comparison, but restrict discussion of down-core isotopic variation to the $\delta^{18} \mathrm{O}$ data.

Low-frequency trends in the distribution of $\delta^{18} \mathrm{O}$ permit us to identify three sequences. First, in units $\mathrm{C}$ and $\mathrm{D}$, there is a linear trend of more depleted ice toward the bed. Secondly, at the contact between units $\mathrm{C}$ and $\mathrm{B}$ there is a sharp change in isotopic content. At the base of unit B the ice is quite depleted, becoming rapidly more enriched up-core. Thirdly, somewhat below the contact between units $\mathrm{B}$ and $\mathrm{A}$, in the convoluted layer, the linear trend is reversed, with unit A more depleted in the upward direction.

In addition, there are high-frequency variations in the $\delta^{18} \mathrm{O}$ signal, sequences of depleted-enriched-depleted ice. These may correspond to individual regelation layers, a point we return to below. There are 12 such identifiable sequences made up of more than three data points. High-

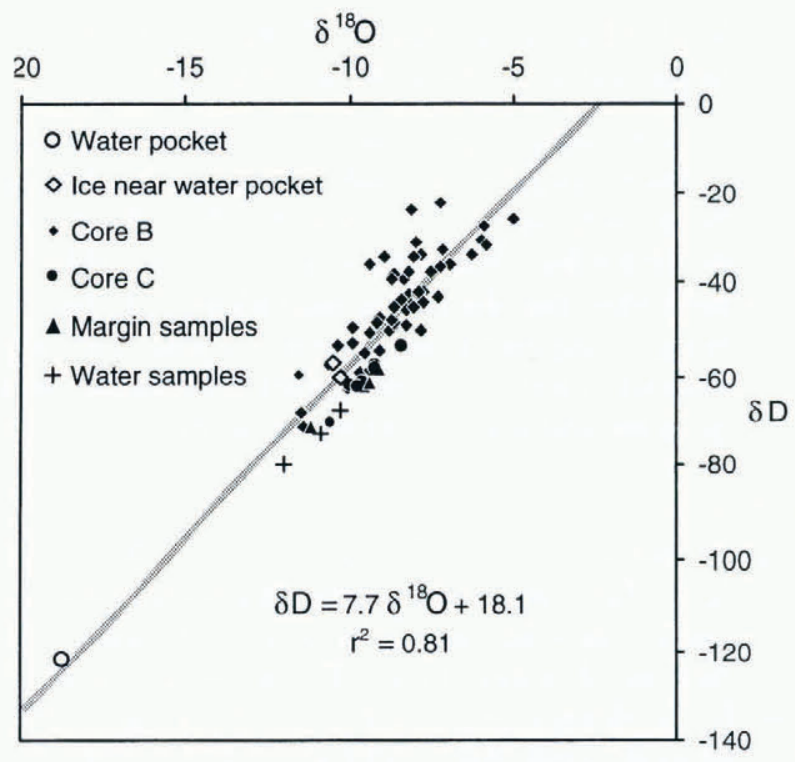

Fig. 5. Co-isotopic composition of basal ice from cores $B$ and $C$, water-pocket sample, ice from near the water pocket, marginal-ice samples and water samples in the area of Engabreen. 
frequency variations are more frequent and of greater magnitude in unit B and in the upper part of unit C, while the signal in unit A is relatively smooth.

Discussion of co-isotopic variation in core B is hampered by the uncertainty in the deuterium analysis. Theoretically there is a linear relation between $\delta^{18} \mathrm{O}$ and $\delta \mathrm{D}$, with distinctly different slopes for ice derived solely from meteoric water and for ice that has been melted and refrozen (Souchez and Lorrain, 1991), but the scatter in the data makes such a conclusion tenuous. What is quite apparent, however, is that the water sample from one of the water pockets is greatly depleted in both isotopes. Oxygen-isotope content of the water is depleted by about $8 \%$ compared with adjacent ice samples, and by about $6 \%$ compared with the most depleted ice samples in core B (Table 1).

\section{DISCUSSION}

There is abundant evidence for regelation in the basal ice beneath Engabreen. The high-frequency variations in isotopic content in units $\mathrm{B}, \mathrm{C}$ and $\mathrm{D}$ resemble simulated isotope signatures obtained by Hubbard and Sharp (1993), who modeled regelation process over a field of bumps of different sizes. Each bump produces a characteristic isotope signal in the regelation layer which is enriched at the top and progressively more depleted toward the base. Because Hubbard and Sharp considered only Weertman regelation, the composite isotope signal of ice flowing over a series of bumps consists of several superimposed characteristic regelation signatures, ordered by the distribution of bump sizes. The signature of the largest bump is altered by the next largest bump, and so on. While it is unclear how Robin-Lliboutry regelation would affect the "master" pattern of a single regelation layer, net accretion would allow down-flow preservation of the isotopic signal in each regelation layer.

There is also evidence for appreciable water movement in the basal layers. This is suggested both by the very presence of water pockets, and by the presence of significantly depleted water in the pockets. While bulk melting normally does not result in fractionation, passage of water isotopes through the vein network may permit fractionation at the crystal boundaries, leading to progressively lighter water finding its way into the water pockets. That the water pockets have higher dissolved-ion values than the surrounding ice also suggests that there is net migration of ion-rich pore water toward the pockets.

Water movement is also implied by the ionic signatures of the different units. Unit A appears to be relatively unaltered glacier ice, with an ionic signature reflecting atmospheric precipitation, i.e., high in $\mathrm{Na}^{+}$ and low in $\mathrm{Ca}^{2+}, \mathrm{Mg}^{2+}$ and $\mathrm{K}^{+}$. Unit $\mathrm{A}$ has similar cation values to those of the ice-margin samples taken from higher up in the vertical column (Table 1).

Close to the contact between units $\mathrm{A}$ and $\mathrm{B}$, and between units $\mathrm{C}$ and $\mathrm{D}, \mathrm{Ca}^{2+}$ and $\mathrm{Mg}^{2+}$ begin to increase gradually toward the contact. We interpret this to be due to diffusion of cations from the sediment-rich layers, with cations transported through the intra-crystalline vein network.

Unit B is clearly distinct from the sediment-poor unit
$\mathrm{C}$ both in sediment concentration and in isotopic signature. $\mathrm{Ca}^{2+}, \mathrm{Mg}^{2+}$ and $\mathrm{K}^{+}$show a weak but identifiable step increase moving up-core from unit $\mathrm{C}$ to $\mathrm{B}$. The fact that this boundary is diffuse and the fact that $\mathrm{Ca}^{2+}, \mathrm{Mg}^{2+}$ and $\mathrm{K}^{+}$are quite high in unit $\mathrm{C}$, despite the relatively low sediment concentrations, again suggest leaching and diffusion of these cations from the sedimentrich unit $\mathrm{B}$. This implies significant downward movement of water through the basal layers, as does the increase in $\mathrm{Na}^{+}$toward the basal ice.

Unit C may thus have been at one time similar to unit $A$, and is simply folded under the sedimentary layers of unit B. Evidence for folding and shearing is by no means uncommon in the basal layers around W1. However, the possibility also exists that the cloudy ice in unit $\mathrm{C}$ is simply regelation ice originating from the lee side of one or more relatively clean bumps. Certainly some of the sedimentary particles we observe in unit $\mathrm{C}$ are too large to have been transported along three-grain intersections, a phenomenon predicted by Lliboutry (1993) and observed by Knight and Knight (1994) for finer sedimentary fractions.

Unit D appears to have been formed more recently than Unit B, based on the higher concentrations of $\mathrm{Ca}^{2+}$, $\mathrm{Mg}^{2+}$ and $\mathrm{K}^{+}$relative to the sediment concentration. The decrease in these cations moving up into unit $\mathrm{C}$ is an indication that upward diffusion is limited and that the net motion of water in the lower basal layers is toward the bed.

\section{CONCLUSION}

Sediment beneath Engabreen is frozen onto the basal ice through the regelation process. Total thicknesses of the sediment-rich basal layers, however, are greater than those which it would be possible to generate in the lee of the largest "controlling" bedrock bump in Weertman regelation theory. This could be taken as evidence for net accretion beneath this part of Engabreen, as could the presence of water pockets which increase in size and degree of elongation with distance from the bed. Ionic signatures, the presence of water pockets and the isotopically depleted and relatively ion-enriched water measured in one of the pockets provide evidence for significant water movement in the basal layers. We conclude, therefore, that regelation ice beneath Engabreen is composed of water that moves at least in part through the intra-crystalline vein system, in the manner proposed by Robin (1976) and developed further by Lliboutry (1993), rather than solely through migration of water along the basal water film described by Weertman (1957).

\section{ACKNOWLEDGEMENTS}

This study was funded by generous grants from the Carl Mannerfelt fund, Andréefonden of the Swedish Society for Anthropology and Geography, and the Axel Hamberg, Hierta-Rietzius' and Th. Nordströms funds of the Royal Swedish Academy of Sciences. Statkraft, the State Power Board, and NVE are gratefully acknowledged for 
putting their facilities at our disposal and for providing logistical support. Comments from A. Iken and P.G. Knight helped to improve the manuscript. Thanks are due to $\mathrm{F}$. Westman at Uppsala for the oxygen and deuterium analyses and to M. Stenberg and A. Öhrström at Stockholm for the cation analysis.

\section{REFERENCES}

Brown, G. H., M.J. Sharp, M. Tranter, A. M. Gurnell and P. W. Nienow. 1994. Impact of post-mixing chemical reactions on the major ion chemistry of bulk meltwaters draining the Haut Glacier d'Arolla, Valais, Switzerland. Hydrological Processes, 8 5), 465 480.

Hubbard, B. and M. Sharp. 1993. Weertman regelation, multiple refreezing events and the isotopic evolution of the basal ice layer. $\mathcal{F}$. Glaciol., 39(132), 275-291.

Knight, P. G. and D. A. Knight. 1994. Correspondence. Glacier sliding. regelation water flow and development of basal ice. \%. Glaciol., 40 136), 600-601.

Knight, P. G., D. E. Sugden and C. D. Minty. 1994. Ice flow around large obstacles as indicated by basal ice exposed at the margin of the Greenland ice sheet. J. Glaciol., 40 (135), 359-367.

Lawson, D. E. 1979. A sedimentological analysis of the western terminus region of the Matanuska Glacier, Alaska. CRREL Rep. 79-9.

Lliboutry, L. 1993. Internal melting and ice accretion at the bottom of temperate glaciers. J. Glaciol., 39 (131), 50-64.

Ostrem, G., N. Haakensen and O. Melander. 1973. Atlas over breer i Nord-Skandinavia Norges Vassdrags - og Elektrisiletsvesen. Hydrologisk Avdeling. Meddelelse 22.

Robin, G. de Q. 1976. Is the basal ice of a temperate glacier at the pressure melting point? J. Glaciol., 16 74), 183-196.

Sharp, M., J. Jouzel, B. Hubbard and W. Lawson. 1994. The character, structure and origin of the basal ice layer of a surge-type glacier. 7 . Glaciol., $40(135), 327-340$.

Souchez, R. A. and J. M. de Groote. 1985. $\delta \mathrm{D} \delta^{18} \mathrm{O}$ relationships in ice formed by subglacial freezing: paleoclimatic implications. J. Glaciol., 31 (109), 229232.

Souchez, R. A. and R.D. Lorrain. 1978. Origin of the basal ice layer from Alpine glaciers indicated by its chemistry. J. Glaciol., 20 83), $319-328$.

Souchez, R.A. and R.D. Lorrain. 1991. Ice composition and glacier d)namics. New York, Springer-Verlag.

Weertman, J. 1957. On the sliding of glaciers. J. Glaciol., 3 21), 33-38. 